\title{
Holding the Line against Diagnostic Inflation in Psychiatry
}

\author{
Laura Batstra $^{a}$ Allen Frances $^{\mathrm{b}}$ \\ a Department of Special Needs Education and Child Care, University of Groningen, Groningen, The Netherlands; \\ ${ }^{b}$ Department of Psychiatry, Duke University Medical Center, Durham, N.C., USA
}

\section{Introduction}

There are converging pressures on psychiatrists, primary care physicians, and other mental health workers to overdiagnose and overtreat mental illness. First, there is a systematic methodological bias that causes all epidemiological studies consistently to report exaggerated rates of mental disorder in the general population [1]. For reasons of cost, such large studies must be conducted using lay interviewers who are unable to judge whether the symptoms they elicit are severe enough to cause clinically significant distress or impairment. The resulting diagnostic inflation gives the false (but widely publicized) impression that psychiatric disorders are frequently missed and are undertreated $[2,3]$. This encourages practitioners to make false-positive diagnoses and to recommend unnecessarily aggressive treatment.

Drug companies greatly amplify this message with clever and aggressive marketing. They have devised the successful strategy of aggressively selling psychiatric ills as the optimal way of peddling psychotropic pills. This is particularly a problem in the USA, which allows direct-to-consumer advertising that has become seemingly ubiquitous. Requests from patients generated by advertising have a profound effect on physician prescribing [4].

Pressure also comes from thought leading experts who routinely promote a widely inclusive definition of their pet diagnoses and from consumer advocacy groups who worry a great deal about false negatives but tend toward indifference about false positives.

The only pushback against all of these pressures causing diagnostic inflation comes from those practice guidelines that suggest a cautious, stepped care approach to treatment $[5,6]$. However, these efforts have not been sufficient to hold the diagnostic line in psychiatry and in primary care practice. Rates of diagnosis and use of psychotropic medication continue to escalate $[2,7]$. Our purpose here is to suggest an explicitly stepped approach to diagnosis that will increase the acceptance and practicality of stepped care for mental disorders. The goal is to reduce the high rate of false positives without risking undertreatment for those who need it.

\section{From Inpatient to Outpatient Psychiatric Diagnosis}

The first manual of mental disorders was developed to collect statistics for the 1860 census in the USA. It described just six conditions, all of which were rare and severe enough to warrant long-term, inpatient hospitalization. Until World War I, it was neurologists working in outpatient settings who diagnosed and treated what are now considered psychiatric disorders, often using the popular neurological labels 'neurasthenia' and 'hys-

\section{KARGER}

Fax +4161306 1234

E-Mail karger@karger.ch

www.karger.com
(C) 2011 S. Karger AG, Basel

0033-3190/12/0811-0005\$38.00/0

Accessible online at:

www.karger.com/pps
Laura Batstra, $\mathrm{PhD}$

Department of Special Needs Education and Child Care

Faculty of Behavioral and Social Sciences, University of Groningen

Grote Rozenstraat 38, NL-9712 TJ Groningen (The Netherlands)

Tel. +31 50363 6585, E-Mail l.batstra@ rug.nl 
teria'. Psychiatrists (aka 'alienists') were confined to 'asylums' and did not see outpatients. Two separate influences together promoted the emergence of outpatient psychiatry and with it the increasing diagnosis of mental disorders in the general population. Freud (a neurologist) expanded Kraepelin's primarily inpatient psychiatric nosology by describing the outpatient presentations of depression, phobias, panic attacks, obsessions, compulsions, personality disorders, conversion reactions, somatic disorders, and perversions. Most of Freud's followers became mental health (not neurological) specialists and practiced in outpatient environments, diagnosing as mental disorders what previously were considered to be neurological diseases. Outpatient psychiatric diagnosis also gained credibility as an explanation for the many emotional disabilities encountered among troops in World War I.

\section{The History of DSM}

The two diagnostic systems in use worldwide are ICD10 (published in 1992) and DSM-IV (published in 1994 and very slightly revised in 2000). Their predecessors DSM-I (published in 1952 in conjunction with ICD 6) and DSM-II (in 1968 with ICD 8A) provided a broad based psychiatric classification that was likely to identify significant rates of psychiatric disorder in the general population. However, lacking any reliable method of psychiatric diagnosis, it was impossible to ascertain just how high these rates might actually be.

Criterion-based diagnosis was introduced as an innovative method to improve reliability, first with the narrowly drawn Feighner criteria in 1972 [8], then expanded in the Research Diagnostic Criteria in 1975 [9], and finally much expanded and made official with the publication of DSM-III in 1980. DSM-III offered a common clinical and research language that made it possible to study the prevalence of mental disorders within the community. It was a splitter's system with many narrowly defined, high prevalence diagnoses.

Not surprisingly, the introduction of DSM-III resulted in a rum of diagnostic inflation that greatly expanded the boundary of mental disorders at the expense of the shrinking province of normality. In the early eighties, an estimated $32 \%$ of the American population was reported to experience at least one life-time episode of DSM-defined disorder [10]. Ten years later, the reported lifetime percentage had jumped to $48 \%$ [11] - a whopping 50\% increase. The estimated lifetime prevalence in
Europe [12] and New Zealand [13] is also high at around $40 \%$.

DSM-IV took a conservative approach aimed at avoiding further exacerbation of diagnostic inflation. Epidemiological studies show that the overall prevalence of psychiatric disorders in adults stabilized $[2,12,14,15]$. Nevertheless, DSM-IV was itself a contributor to three false-positive 'epidemics': adult bipolar disorders, attention deficit hyperactivity disorder, and autistic disorder $[16,17]$. The troubling epidemic of childhood bipolar disorder occurred independently of DSM-IV under pressure from thought leaders and drug company marketing.

\section{It Gets Worse in Prospective Studies}

The extent of diagnostic inflation varies with the method used to study it. Reported rates of psychiatric disorder in the general population are extremely sensitive to how the diagnoses are made. Because of faulty respondent recalls, retrospective surveys significantly underestimate lifetime prevalences. Moffitt et al. [18] found that lifetime prevalence rates doubled when measured prospectively. By age 32 , prospectively evaluated subjects had the remarkably high lifetime rates of almost $50 \%$ for anxiety disorder, more than $40 \%$ for depression, and more than $30 \%$ for alcohol dependence. The extent of diagnostic inflation is revealed in the most recent NIMH figures suggesting that $26 \%$ of the US general population meet criteria for a mental disorder in any given year [19]. This figure translates to 57.7 million people aged 18 and older [20].

It is extremely unlikely that we are witnessing any true increase in morbidity. Human nature changes slowly, if at all. In contrast, diagnostic labels and ways of assessing them are extremely elastic and malleable to current fashion. Clearly there has been a massive relabeling, expanding the concept of mental illness to include symptoms and behaviors that previously were considered an unpleasant, but expectable, part of everyday life. Unless these trends are somehow reversed, it will soon be difficult for anyone to live a lifetime without qualifying for one or several mental disorders.

\section{The Dangers of DSM-5}

Unfortunately, DSM-5, scheduled to appear in May 2013, proposes another grand expansion of mental illness $[17,21]$, with suggestions that taken together may create 
tens of millions of additional new patients, all by arbitrary diagnostic fiat. This will happen in three ways. First, DSM-5 plans to introduce five new, high prevalence disorders at the populous and fuzzy boundary with normality (mixed anxiety depression, binge eating, mild neurocognitive, mood dysregulation, and attenuated psychotic symptoms). Second, DSM-5 will reduce thresholds in the criteria sets of very common disorders in a way that may make them much more common (especially generalized anxiety and adult attention deficit). Finally, creating spectrums of autism and addictions will likely broaden their purview.

The DSM-5 principle has been to avoid false negatives at all costs and to worry not at all about false positives. In contrast, we believe the false positive problem in psychiatric diagnosis is now far worse than the false negative problem. Certainly many severely suffering potential patients do not get the treatment they could clearly benefit from, but this is not due to diagnostic thresholds being set too high and it will not be corrected by creating new and unproven mild boundary disorders. On the other hand, false-positive diagnoses create huge and obvious problems: unnecessary, harmful, and expensive treatments; stigma; lowered expectations and a reduced sense of personal responsibility; misallocation of resources from the really ill to the worried well; difficulties getting insurance; excessive disability; forensic complications, and more.

\section{The Fuzzy Boundary with Normality}

The most difficult diagnostic challenge is at the fluid boundary separating mental illness from the inevitability of human unhappiness and the difficulties caused by deviant behaviors. In psychiatry, diagnostic validity is absent for most disorders: there are no laboratory tests to establish the presence or absence of a given mental disorder [22, 23]. Only one quarter of cases have an illness that is severe enough to meet anyone's definition of clinical significance [24]. The proportion of questionable subthreshold cases is substantial (over a third in the USA and more than half in Europe). These questionable cases are precisely the ones who are most in need of stepped diagnosis before jumping the gun toward a definitive labeling.

Two thirds of people meeting criteria for a DSM disorder do not receive treatment $[3,19]$. This is usually interpreted as evidence of undertreatment, but a plausible alternative possibility is that many were overdiagnosed in large epidemiological studies using lay interviewers and are not really ill enough to want or need help. Unnecessary treatment of mild, subthreshold, and noncases results in unnecessary side effects, stigma, cost, and a misallocation of mental health services $[2,3]$.

\section{Drug Companies Promote IIIness}

The rate of pharmacotherapy has increased dramatically $[2,7]$. Drug companies have had remarkable success in making psychotropic drugs a part of everyday life. In 2009 , antipsychotics reigned as the top-selling class of all medications in the USA, accounting for fully $5 \%$ of all prescriptions written and generating USD 14.6 billion of revenue [25]. Antidepressants were not far behind - the fourth largest selling class - capturing USD 9.9 billion. The drug companies are ubiquitous players in psychiatry, influencing thought leaders and consumer advocacy groups, monopolizing professional 'education', lavishing trips and meals, clogging physicians waiting rooms with attractive salespeople, stocking doctors with free samples, and (in the USA) conducting direct-to-consumer promotional campaigns in the print media, on TV, and on the Internet. The promotional influence far transcends psychiatrists. Most prescribing of psychotropic medicine is done by primary care doctors diagnosing and treating mental disorders in visits that last under $10 \mathrm{~min}$.

While drug company influence is endemic throughout medicine, overdiagnosis and overtreatment of mental disorders is of particular concern because diagnostic decisions are based mostly on patient self-report, not on objective signs or laboratory tests [22, 23]. Psychiatric diagnosis is thus especially vulnerable to muscular marketing efforts to medicalize normal human experiences and to promote oversimplified neurobiological models for the understanding and treatment of mental disorders. Biological and pharmaceutical reductionisms have led to undertreatment, overtreatment, and mistreatment of mental problems [26].

\section{Allocation of Scarce Resources}

The cheapened currency of psychiatric diagnosis leads to much unnecessary pharmaceutical and intensive psychological treatment delivered to false-positive 'nonpatients'. In the severely mentally ill, the benefits of medication and intensive psychological treatment clearly out- 
weigh the risks and costs. In the mildly or not really ill, the risks and costs often outweigh the benefits [27]. The efficacy of psychotropic medications has been established in studies of moderately to severely ill patients. Less severe cases enjoy such high placebo response rates that it is difficult to demonstrate any additional gain from more active treatment [28].

Research has shown that psychiatrists would prefer less invasive treatments for themselves but recommend more invasive ones for their patients [29]. Doctors are more likely to be held responsible for negative consequences of undertreatment (e.g. a suicide attempt) and are seldom criticized for false-positive diagnoses that lead to unnecessary and expensive interventions.

The medicalization of normal human behavior redirects resources that would be much better used for treating those with severe mental illness who are most in need of help. Providing treatment for the mildly ill (and for those who are not really ill at all) deprives those with severe illness. Economic exigency dictates that we return to a more efficient resource allocation.

Of course, it can be argued that the strategy of not treating any mild cases would also be suboptimal since some will eventually progress into more severe disorders [30]. Indeed, treating mild cases is cost effective whenever this prevents them from getting worse, but it makes no sense at all if the 'patient' might recover with time or minimal intervention. Stepped diagnosis provides an ideal method of reducing overtreatment of those who might recover with minimal interventions, without risking undertreatment of those who would get worse without early intervention.

\section{Stepped Diagnosis to the Rescue}

Stepped diagnosis and treatment are based on a model of health care delivery in which the first-line efforts are the least intensive of those available that are still likely to provide a significant health gain [31,32]. More definitive diagnoses and expensive treatments are preserved for people who are not able to benefit from the simpler, stepped, first-line interventions. Continuous assessments of the patient's condition are crucial - with timely 'stepping up' if a lesser intervention is not achieving a significant health gain.

Stepped care is particularly feasible and indicated for less severe cases where the diagnosis of mental disorder is inherently uncertain and unreliable. In contrast, early diagnosis and intensive treatment is possible, required, and cost effective whenever the problems are urgent, severe, recurrent, or clear-cut.

Stepped care starts with a stepped diagnosis. Prior to a definitive diagnosis, the primary care doctor or mental health professional takes the following steps: (1) Gather baseline data. For moderate and severe problems go directly to step 6 . For mild, first-onset, and/or stress reactive problems continue to the next step. (2) Normalize problems without devaluing or minimizing the patient's pain or distress [33]. Reassure the patient that his or her emotions are an expectable response to the stressors in his or her life. Speak in terms of 'problems' or 'difficulties', actively avoid terms like 'depression' or 'psychiatric illness'. (3) Watchful waiting - a period of continued assessment, monitoring, and scheduled follow-up with no pretence of a definitive diagnosis or active treatment [34]. (4) Minimal interventions aimed at stress reduction, such as bibliotherapy or computer-aided therapy [32]. Make explicit that these are not offered to treat a psychiatric disorder that has already been defined. A major advantage of these minimal interventions is that they harness the person's capacity for self-help as much as possible [32]. (5) Brief counseling - simple techniques derived from cognitive behavior therapy [35], problem solving therapy [35], or solution-focused brief therapy [36] to teach new attitudes and coping skills in dealing with stressors. (6) The definitive diagnosis is made and definitive treatment is begun whenever symptoms persist to cause clinically significant distress or impairment.

Although step 6 and further is beyond the scope of this paper, we think it is important to stress that the process of (pre)diagnostic reasoning does not end with a DSM diagnosis and pharmaceutical treatment [37]. A DSM diagnosis should be the beginning of a diagnostic process and individualized treatment in which psychotherapeutic interventions may follow pharmacological treatment and vice versa.

\section{Conclusion}

Stepped diagnosis is a tool to help physicians and mental health workers make more accurate diagnoses and to reduce the provision of unnecessary and possibly harmful treatment. It is intended to reduce false-positive diagnoses and consequential artificially elevated rates of mental illness without risking missed diagnosis and undertreatment. It should also improve the allocation of resources by redirecting diagnosis and care away from 
those who do not really need them towards those who really do. Mild psychiatric presentations often resolve with the passage of time, placebo effect, and minor interventions. It is cost and stigma saving to adequately reimburse careful evaluations as a means of reducing overdiagnosis and avoiding unnecessarily intensive treatments. Stepped diagnosis will become even more important if DSM-5 opens the floodgates further and especially when drug companies direct their aggressive marketing to the new target disorders and lowered diagnostic thresholds offered by DSM-5. Psychiatry can enhance its credibility and improve its results by sticking to its appropriate target population of the moderately and severely ill. Stepped diagnosis will keep the worried well from being mislabeled as mentally disordered.

\section{Disclosure Statement}

Allen Frances was chair of the DSM-IV Task Force and coauthor of several books related to the use of DSM-IV. Laura Batstra reports no conflicts of interest.

\section{References}

1 Frances A: Problems in defining clinical significance in epidemiological studies. Arch Gen Psychiatry 1998;55:119.

-2 Kessler RC, Demler O, Frank RG, Olfson M, Pincus HA, Walters EE, Wang P, Wells KB, Zaslavsky AM: Prevalence and treatment of mental disorders, 1990 to 2003. N Engl J Med 2005;352:2515-2523.

3 Wang PS, Aguilar-Gaxiola S, Alonso J, Angermeyer MC, Borges G, Bromet EJ, Bruffaerts R, de Girolamo G, de Graaf R, Gureje O, Haro JM, Karam EG, Kessler RC, Kovess $\mathrm{V}$, Lane MC, Lee S, Levinson D, Ono Y, Petukhova M, Posada-Villa J, Seedat S, Wells JE: Use of mental health services for anxiety, mood, and substance disorders in 17 countries in the WHO world mental health surveys. Lancet 2007;370:841-850.

$\checkmark 4$ Kravitz RL, Epstein RM, Feldman MD, Franz CE, Azari R, Wilkes MS, Hinton L, Franks P: Influence of patients' requests for direct-to-consumer advertised antidepressants: a randomized controlled trial. JAMA 2005;293:1995-2002.

5 National Institute for Health and Clinical Excellence: Depression: the treatment and management of depression in adults - clinical guideline 90. 2009. http://guidance.nice. org.uk/CG90/NICEGuidance/pdf/English (accessed April 6, 2011).

-6 Spijker J, van Vliet IM, Meeuwissen JA, van Balkom AJ: Update of the multidisciplinary guidelines for anxiety and depression (article in Dutch). Tijdschr Psychiatr 2010;52: 715-718.

7 Jenkins R, Meltzer H, Bebbington P, Brugha T, Farrell M, McManus S, Singleton N: The British Mental Health Survey Programme: achievements and latest findings. Soc Psychiatry Psychiatr Epidemiol 2009;44:899-904.

-8 Feighner JP, Robins E, Guze SB, Woodruff RA Jr, Winokur G, Munoz R: Diagnostic criteria for use in psychiatric research. Arch Gen Psychiatry 1972;26:57-63.
-9 Spitzer RL, Endicott J, Robins E: Research diagnostic criteria. Psychopharmacol Bul 1975;11:22-25.

10 Robins LN, Helzer JE, Weismann MM, Orvaschel H, Gruenberg E, Burke JD Jr, Regier DA: Lifetime prevalence of specific psychiatric disorders in three sites. Arch Gen Psychiatry 1984;41:949-958.

11 Kessler RC, Berglund P, Demler O, Jin R, Merikangas KR, Walters EE: Lifetime prevalence and age-of-onset distributions of DSM-IV disorders in the National Comorbidity Survey Replication (NCS-R). Arch Gen Psychiatry 2005;62:593-602.

12 de Graaf R, Ten Have M, van Gool C, van Dorsselaer S: Prevalence of mental disorders and trends from 1996 to 2009: results from the Netherlands Mental Health Survey and Incidence Study - 2. Soc Psychiatry Psychiatr Epidemiol 2011, E-pub ahead of print.

13 Oakley Browne MA, Wells JE, Scott KM: Te Rau Hinengaro: The New Zealand Mental Health Survey. Wellington, Ministry of Health, 2006.

14 Brugha TS, Bebbington PE, Singleton N, et al: Trends in service use and treatment for mental disorders in adults throughout Great Britain. Br J Psychiatry 2004;185:378-384.

15 Slade T, Johnston A, Oakley Browne MA, Andrews G, Whiteford H: National Survey of Mental Health and Wellbeing: methods and findings. Aust NZ J Psychiatry 2009;43: 594-605.

16 Frances A: A warning sign on the road to DSM-V: beware of its unintended consequences. 2009. http://www.psychiatrictimes. com/print/article/10168/1425378?printable $=$ true.

17 Frances A: The First draft of DSM-V. BMJ 2010;340:c1168.

18 Moffitt TE, Caspi A, Taylor A, Kokaua B, Milne BJ, Polanczyk G, Poulton R: How common are common mental disorders? Evidence that lifetime prevalence rates are doubled by prospective versus retrospective ascertainment. Psychol Med 2010;40:899-909.
19 Kessler RC, Chiu WT, Demler O, Walters EE: Prevalence, severity, and comorbidity of twelve-month DSM-IV disorders in the National Comorbidity Survey Replication (NCS-R). Arch Gen Psychiatry 2005;62:617627.

20 US Census Bureau: Population estimates by demographic characteristics. Table 2: annual estimates of the population by selected age groups and sex for the United States - April 1, 2000 to July 1, 2004 (NC-EST200402). 2005. http://www.census.gov/popest/ national/asrh/.

21 Frances A: Whither DSM-V? Br J Psychiatry 2009; 195:391-392.

22 Burger H, Neeleman N: A glossary on psychiatric epidemiology. J Epidemiol Community Health 2007;61:185-189.

23 Rounsaville B, Alarcon RD, Andrews G, Jackson JS, Kendell RE, Kendler K: Basic nomenclature issues for DSM-V; in Kupfer D, First M, Regier D (eds): A Research Agenda for DSM-V. Washington, American Psychiatric Publishing, 2002, pp 1-30.

24 World Mental Health Survey Consortium: Prevalence, severity, and unmet need for treatment of mental disorders in the World Health Organization World Mental Health Surveys. JAMA 2004;291:2581-2590.

25 IMS: IMS health reports. 2011. http://www. imshealth.com/portal/site/imshealth/menuitem.a46c6d4df3db4b3d88f611019418c22 a/?vgnextoid=d690a27e9d5b7210VgnVCM1 00000ed152ca2RCRD.

26 Fava GA: The decline of pharmaceutical psychiatry and the increasing role of psychological medicine. Psychother Psychosom 2009; 78:220-227.

27 Baumeister $\mathrm{H}$ : Inappropriate prescriptions of antidepressant drugs in patients with subthreshold to mild depression: time for the evidence to become practice. J Affect Disord DOI: 10.1016/j.jad.2011.05.025. 
>28 Fournier JC, DeRubeis RJ, Hollon SD, Dimidjian S, Amsterdam JD, Shelton RC, Fawcett J: Antidepressant drug effects and depression severity: a patient-level meta-analysis. JAMA 2010;303:47-53.

-29 Mendel R, Hamann J, Traut-Mattausch E, Bühner M, Kissling W, Frey D: 'What would you do if you were me, doctor?': Randomised trial of psychiatrists' personal v. professional perspectives on treatment recommendations. Br J Psychiatry 2010;197:441-447.

30 Kessler RC, Merikangas KR, Berglind P, Eaton WW, Koretz DS, Walters EE: Mild disorders should not be eliminated from the DSM-5. Arch Gen Psychiatry 2003;60:11171122.
31 Bower P, Gilbody S: Stepped care in psychological therapies: access, effectiveness and efficiency - narrative literature review. Br J Psychiatry 2005;186:11-17.

32 Marks I: Mental health clinics in the 21st century. Psychother Psychosom 2009;78: $133-138$

33 Geldard K, Geldard G: Personal Counseling Skills: An Integrative Approach. Illinois, Charles C Thomas, 2008.
34 Meredith LS, Cheng WJY, Hicky SC, DwightJohnson M: Factors associated with primary care clinician's choice of a watchful waiting approach to managing depression. Psychiatr Serv 2007;58:72-78.

35 Cape J, Whittington C, Buszewicz M, Wallace $\mathrm{P}$, Underwood L: Brief psychological therapies for anxiety and depression in primary care: meta-analyses and meta-regression. BMC Med 2010;8:38.

>36 Gingerich WJ, Eisengart S: Solution-focused brief therapy: a review of the outcome research. Fam Process 2000;39:477-498.

\37 Fava GA, Tomba E: New modalities of assessment and treatment planning in depression. CNS Drugs 2010;24:1-13. 